\title{
Telomere Length Recovery: A Strong Predictor of Overall Survival in Acute Promyelocytic Leukemia
}

\author{
Muhamed Baljevic $^{a} \quad$ Bogdan Dumitriu $^{b} \quad$ Ju-Whei Lee ${ }^{c}$ Elisabeth M. Paietta ${ }^{d}$ \\ Peter H. Wiernik $^{\mathrm{e}}$ Janis Racevskis ${ }^{d}$ Christina Chen $^{\mathrm{b}}$ Eytan M. Stein ${ }^{\mathrm{f}}$ \\ Robert E. Gallagher ${ }^{d}$ Jacob M. Rowe ${ }^{g}$ Frederick R. Appelbaum ${ }^{\mathrm{i}}$ \\ Bayard L. Powell ${ }^{j}$ Richard A. Larson ${ }^{\text {h }}$ Steven E. Coutrék Jeffrey Lancet ${ }^{1}$ \\ Mark R. Litzow $^{m}$ Selina M. Luger ${ }^{n}$ Neal S. Young ${ }^{b}$ Martin S. Tallman ${ }^{f}$ \\ ${ }^{a}$ Oncology/Hematology Division, The University of Nebraska Medical Center, Omaha, Nebr., b National Heart, \\ Lung, and Blood Institute, National Institutes of Health, Bethesda, Md., ' Dana Farber Cancer Institute -

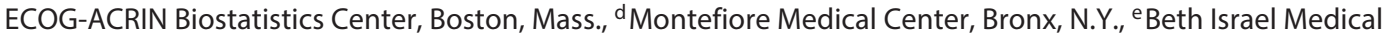 \\ Center and ${ }^{\mathrm{f}}$ Memorial Sloan Kettering Cancer Center, New York, N.Y., ${ }^{g}$ Rambam Medical Center, Northwestern

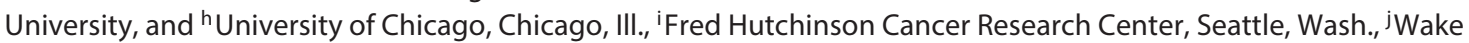 \\ Forest Baptist Comprehensive Cancer Center, Winston-Salem, N.C., ${ }^{~}$ Stanford University, Stanford, Calif., 'Moffitt

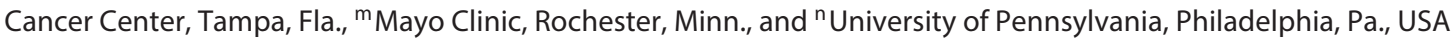

\section{Key Words}

Acute promyelocytic leukemia · Disease risk factors .

Telomere length

\begin{abstract}
Telomeres are the capping ends of chromosomes that protect the loss of genetic material and prevent chromosomal instability. In human tissue-specific stem/progenitor cells, telomere length ( $T L$ ) is maintained by the telomerase complex, which consists of a reverse transcriptase catalytic subunit (TERT) and an RNA template (TERC). Very short telomeres and loss-of-function mutations in the TERT and TERC genes have been reported in acute myeloid leukemia, but the role of telomeres in acute promyelocytic leukemia (APL) has not been well established. We report the results for a
\end{abstract}

E-Mail karger@karger.com www.karger.com/aha

\section{KARGER}

large cohort of 187 PML/RARa-positive APL patients. No germline mutations in the TERT or TERC genes were identified. Codon 279 and 1062 TERT polymorphisms were present at a frequency similar to that in the general population. TL measured in blood or marrow mononuclear cells at diagnosis was significantly shorter in the APL patients than in healthy volunteers, and shorter telomeres at diagnosis were significantly associated with high-risk disease. For patients who achieved complete remission, the median increase in TL from diagnosis to remission (delta TL) was 2.0 kilobase (kb), and we found delta TL to be the most powerful predictor of overall survival when compared with well-established risk factors for poor outcomes in APL.

(c) 2016 S. Karger AG, Basel
M.B. and B.D. contributed equally to this work.
(C) 2016 S. Karger AG Basel

$0001-5792 / 16 / 1364-0210 \$ 39.50 / 0$ 


\section{Introduction}

Telomeres are composed of tandem hexameric TTAGGG nucleotide repeats that protect them from the loss of genetic material due to end-replication deficiency of the DNA polymerase, as well as conferring stability to the chromosome ends. Telomeres are maintained by the telomerase enzyme complex, made up of a reverse transcriptase catalytic subunit (TERT) and an RNA template (TERC) [1]. TERT enzymatically adds TTAGGG nucleotide repeats to the $3^{\prime}$ end of the telomere leading strand by using TERC as a template. Present in very specific cells, such as embryonic and adult stem cells, telomerase elongates the linear telomeric sequence by the addition of new hexameric repeats, thus slowing the attrition rate of telomeric repeats and preventing replicative cellular aging. Loss-of-function mutations in the telomerase complex genes lead to telomere shortening in humans, and have been linked to the malignant transformation and alteration of normal bone marrow hematopoiesis [2]. Telomerase activity is also often increased in neoplastic cells and is important for continuous cancer cell proliferation in human malignancies [3]. Though very short telomeres and germline mutations in the TERT and TERC genes have been associated with acute myeloid leukemia (AML) [4], the association between telomere length (TL) or telomerase complex integrity and outcomes in patients with acute promyelocytic leukemia (APL) has not been thoroughly analyzed.

The majority of patients with APL are characterized by a balanced reciprocal translocation between the long arms of chromosomes 15 and 17, giving rise to the novel PML/RARa fusion gene. Currently, APL is effectively treated with the cell differentiation inducer, all-trans retinoic acid (ATRA) and with arsenic trioxide (ATO) [5]. In vitro studies have demonstrated that the success of ATRA/ATO treatment may, at least in part, be explained by the synergistic effect in triggering the downregulation of the telomerase enzyme, leading to TL shortening and subsequent cell death [6]. The association between TL and telomerase activity in patients with APL has been addressed sporadically, one report recognizing that shortened TL and elevated telomerase activity in APL patients correlate with inferior overall survival (OS) [7].

Mutations in the human TERT and TERC genes have been described in dyskeratosis congenita and other bone marrow failure syndromes [8-10], placing these patients at a high risk of secondary malignant transformations [11]. The link between mutations in the TERT and TERC genes in association with APL is anecdotal, with only a few APL patients reported with TERT gene polymorphisms among a larger group of AML patients [4].

This report describes the largest analysis to date of TL and germline mutations in TERT and TERC in mononuclear cells (MNCs) from the blood or bone marrow of APL patients at all stages of disease including the time points diagnosis, complete remission (CR) and relapse. We measured TL and delta TL, i.e. the difference between TL in MNCs at diagnosis and in remission, in comparison with clinical and laboratory parameters, including disease risk status defined by presenting the white blood cell (WBC) count, early mortality, achievement of CR, disease-free survival (DFS) and OS.

\section{Materials and Methods}

\section{APL Cohort}

One hundred and eighty-seven previously untreated APL patients enrolled in the intergroup trials E2491, C9710, S0521 and S0535, with available DNA from blood or bone marrow MNCs from the ECOG-ACRIN Leukemia Tissue Bank, were included in this study. E2491 was a phase III randomized study of ATRA versus cytosine arabinoside and daunorubicin as induction therapy in both high- and low-risk patients [12]. C9710 was a phase III randomized study of concurrent ATRA and chemotherapy with or without ATO as initial consolidation therapy followed by maintenance therapy with intermittent ATRA versus intermittent ATRA plus mercaptopurine and methotrexate [5]. S0521 was a phase III randomized trial of maintenance versus observation for low and intermediate risk APL. S0535 was a phase II study of ATRA, ATO and gemtuzumab ozogamicin in high-risk APL (both S0521 and S0535 are ongoing, but are no longer recruiting participants). The diagnosis of APL was established based on the presence of PML/ RAR $\alpha$ by qualitative polymerase chain reaction (PCR). Disease risk groups were defined as: low-risk $\left(\mathrm{WBC} \leq 10 \times 10^{9} / \mathrm{l}\right)$ and highrisk $\left(\mathrm{WBC}>10 \times 10^{9} / \mathrm{l}\right)$ [5]. All studies were carried out in accordance with local institution-approved regulations and informed written consent was obtained from each patient. TL in the APL samples was compared with samples from healthy, age-matched controls.

\section{TERT/TERC Sequencing and TL Assay}

DNA was isolated from Ficoll-Hypaque-separated MNCs using the Qiagen DNA isolation kit. Mean TL was measured by a validated, CLIA-certified quantitative PCR method, using the RotorGene SYBR Green kit (Qiagen) [13]. Relative TL was calculated by generating a ratio between total telomere DNA (T) and DNA from amplification of a single copy gene $(S)$, thereby providing a relative $\mathrm{T} / \mathrm{S}$ ratio normalized to the reference sample. Age-adjusted TL was calculated using 299 healthy volunteers, ages 0-99, for whom TL was measured from peripheral blood leukocytes. All healthy volunteers were enrolled in clinical research trials at the National Heart, Lung, and Blood Institute. Mean telomere content by quantitative PCR and Sanger sequencing of TERC and TERT were performed as previously described $[4,5]$. For ease of reading, we refer to mean telomere content as TL throughout this paper. 
Table 1. Pretreatment characteristics for 190 patients with telomere data

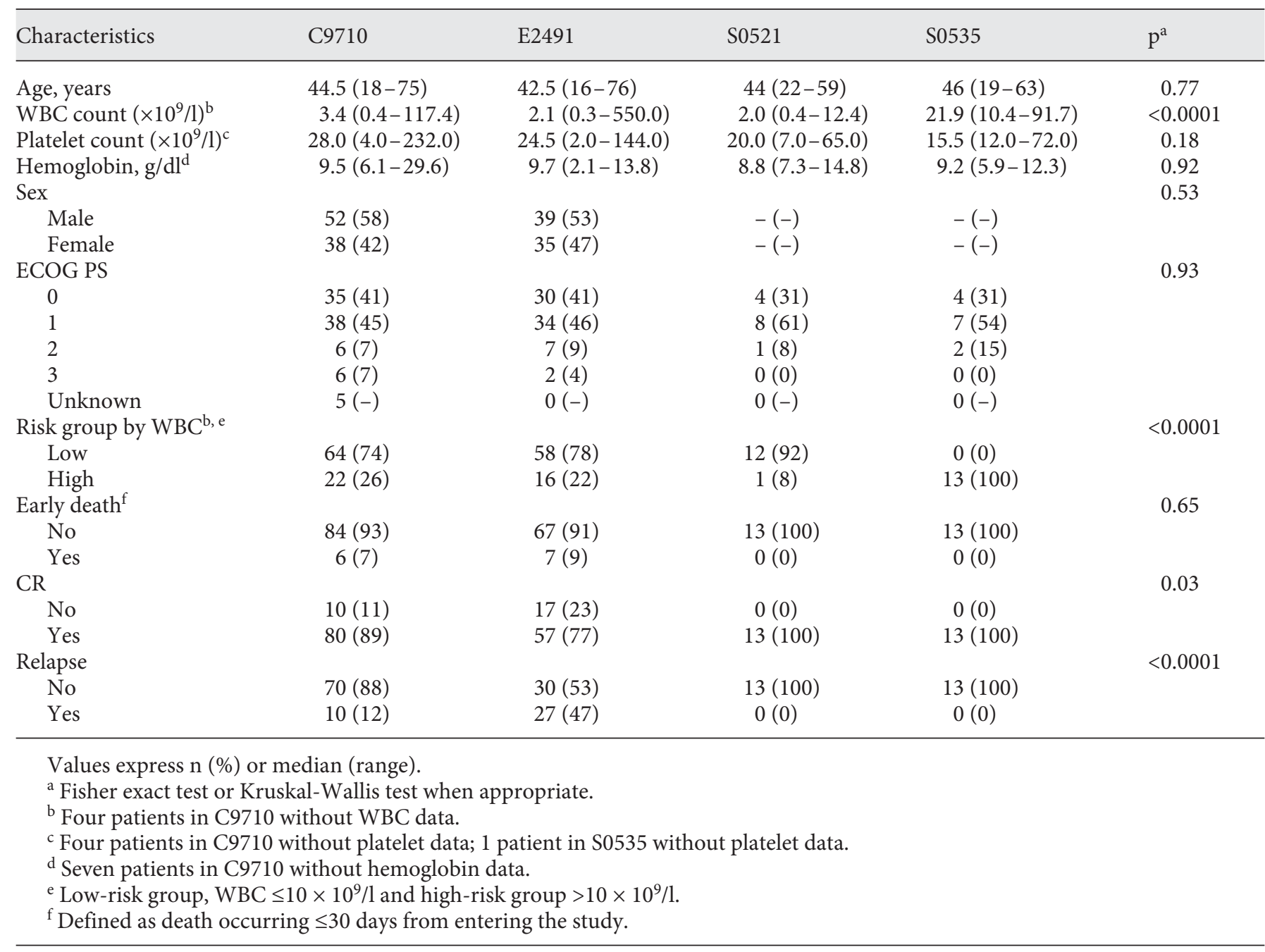

\section{Statistical Analysis}

Patient demographic factors and laboratory parameters were compared across groups using the Fisher exact test and the Kruskal-Wallis test when appropriate. The Spearman correlation was calculated between numeric variables. OS was measured from study entry to death from any cause with follow-up censored at the date of last contact. DFS was defined as the time from hematologic CR to relapse or death from any cause, whichever occurred earlier. Patients without documented relapse or death reported were censored at the time of last contact. Given the heterogeneity of the study and treatment schedules, the analysis performed here was stratified by the combination of study and treatment. To examine the association between TL and clinical outcomes, the odds ratio (OR) and its corresponding 95\% confidence interval (CI) were calculated using stratified logistic models. OS and DFS were estimated using the Kaplan-Meier method and compared using stratified log-rank tests. Hazard ratios (HRs) were computed and tested using stratified univariate and multivariable Cox proportional-hazards $(\mathrm{PH})$ models, with ECOG performance status (PS, 0 vs. 1 vs.
2-3), WBC risk status (low vs. high), age, and platelet and hemoglobin counts serving as covariates in the multivariable model. The Cox PH models with forward selection (with the entry criterion set at 0.20 ) were used to find the most potent predictor of OS and DFS. All reported $p$ values are 2 -sided. A level of $5 \%$ was considered statistically significant.

\section{Results}

\section{Patient Characteristics}

Patient pretreatment characteristics by study are presented in table 1. Median follow-up for survivors among the 187 patients was 3.9 years (range $0-14.5$ years), from the time of study enrollment. No statistically significant differences were observed in age, sex, ECOG PS, platelet 
Table 2. TL (kb) across studies at various time points

\begin{tabular}{lllllll}
\hline Time point & N & Median & Q1 & Q3 & Minimum & Maximum \\
\hline Diagnosis & 187 & 5.1 & 4.6 & 5.6 & 3.9 & 7.7 \\
Remission & 143 & 7.2 & 6.7 & 8.1 & 4.6 & 13.2 \\
Delta TL $^{1}$ & 140 & 2.0 & 1.3 & 2.7 & 0.1 & 7.1 \\
Relapse & 18 & 6.5 & 5.5 & 8.4 & 4.5 & 10.3 \\
\hline
\end{tabular}

${ }^{1}$ Defined as TL at remission minus TL at diagnosis.

Table 3. TL (kb) by study and time point

\begin{tabular}{|c|c|c|c|c|c|c|c|c|c|}
\hline \multirow[t]{2}{*}{ Time point } & \multicolumn{2}{|c|}{ C9710 } & \multicolumn{2}{|c|}{$\mathrm{E} 2491$} & \multicolumn{2}{|c|}{ S0521 } & \multicolumn{2}{|c|}{ S0535 } & \multirow[t]{2}{*}{$\mathrm{p}^{1}$} \\
\hline & $\mathrm{n}$ & length & $\mathrm{n}$ & length & $\mathrm{n}$ & length & $\mathrm{n}$ & length & \\
\hline Diagnosis & 90 & $5.0(3.9-6.9)$ & 71 & $5.3(4.1-7.7)$ & 13 & $5.7(4.6-6.4)$ & 13 & $4.8(4.2-7.2)$ & 0.002 \\
\hline Remission & 72 & $6.9(4.6-10.7)$ & 45 & $7.8(5.1-13.2)$ & 13 & $7.4(6.4-9.2)$ & 13 & $7.1(5.4-9.9)$ & 0.002 \\
\hline Delta $\mathrm{TL}^{2}$ & 72 & $1.9(0.1-4.5)$ & 42 & $2.3(0.1-7.1)$ & 13 & $1.9(0.6-3.5)$ & 13 & $2.3(0.6-4.8)$ & 0.32 \\
\hline Relapse & 5 & $6.0(4.5-6.9)$ & 13 & $6.9(4.6-10.3)$ & 0 & - & 0 & - & 0.08 \\
\hline
\end{tabular}

Values are expressed as median (range).

${ }^{1}$ Kruskal-Wallis test.

${ }^{2}$ Defined as TL at remission minus TL at diagnosis.

or hemoglobin values at baseline in the 4 studies but WBC count was statistically different, whether characterized by the numerical values on the continuous scale (medians of 3.4, 2.1, 2.0 and $21.9 \times 10^{9} / 1$ for C9710, E2491, S0521 and S0535, respectively; $\mathrm{p}<0.001$ ) or by risk status. Early death (defined as death occurring $\leq 30$ days from entering the study), CR and relapse status by study are also summarized in table 1 . Although there was no statistically significant difference in early mortality rate across the 4 studies ( $\mathrm{p}=0.65)$, a significant difference was noted with respect to CR $(\mathrm{p}=0.03)$ and relapse status $(\mathrm{p}<0.0001)$.

\section{TL at Diagnosis, Remission and Relapse of APL}

Quantitative PCR measurements of TL in kilobase $(\mathrm{kb})$ pairs was performed at various disease time points across all 4 studies in patients who had samples available for the extraction of DNA, and the results are presented in table 2 . Of 187 patients analyzed at diagnosis, $143 \mathrm{had}$ DNA available in hematologic and molecular CR (PML/ RARa-negative) and 18 at relapse. At diagnosis, DNA was extracted from blood or bone marrow MNCs that contained a median of $75 \%$ (range 13-99\%) of leukemic promyelocytes. No statistically significant association between TL at presentation and the percentage of leukemic promyelocytes at presentation was observed $(\mathrm{p}=0.12$; $\mathrm{n}=172$ for all 4 studies).

Telomere Biology in APL
TL at diagnosis was significantly different in all 4 studies $(p=0.002$; table 3$)$. Similar results were observed for TL in remission $(\mathrm{p}=0.002)$. Specifically, patients in S0535 had the lowest TL distribution at diagnosis (median 4.8, range $4.2-7.2 \mathrm{~kb}$ ) and those in S0521 had the highest TL distribution (median 5.7, range 4.6-6.4 kb), echoing the risk status of APL patients in these studies. Delta TL, i.e. the change in TL at the time of diagnosis of APL to the time of CR, was not significantly different across the 4 studies $(\mathrm{p}=0.32)$. $\mathrm{TL}$ at relapse was only available for 5 patients from C9710 and 13 patients from E2491, and it demonstrated no statistically significant difference in TL between these 2 studies $(p=0.08)$. TL at diagnosis was significantly shorter in the APL samples than in the samples from healthy controls (median 5.1, range 3.9-7.7 kb vs. median 7.8, range 5.3$14.2 \mathrm{~kb} ; \mathrm{p}<0.0001$; fig. 1a). For patients in CR, the median delta TL was $2.0 \mathrm{~kb}$ (range $0.1-7.1 \mathrm{~kb}$; signed rank test against $0, p<0.0001$; fig. $1 \mathrm{~b}$ ); however, TL at remission in these patients was still shorter than that in the age-matched healthy control subjects (median 7.2, range 4.6-13.2 kb vs. $7.8 \mathrm{~kb} ; \mathrm{p}<0.0001$ ). We observed a statistically significant increase in TL from the time points of diagnosis to relapse (median 5.1 vs. $6.5 \mathrm{~kb} ; \mathrm{p}=0.005 ; \mathrm{n}=16$ ). However, no significant decrease in TL was found between CR and relapse (median 7.2 vs. $6.5 \mathrm{~kb} ; \mathrm{p}=0.10$ ). It must be noted that this finding was based on 14 patients only. 


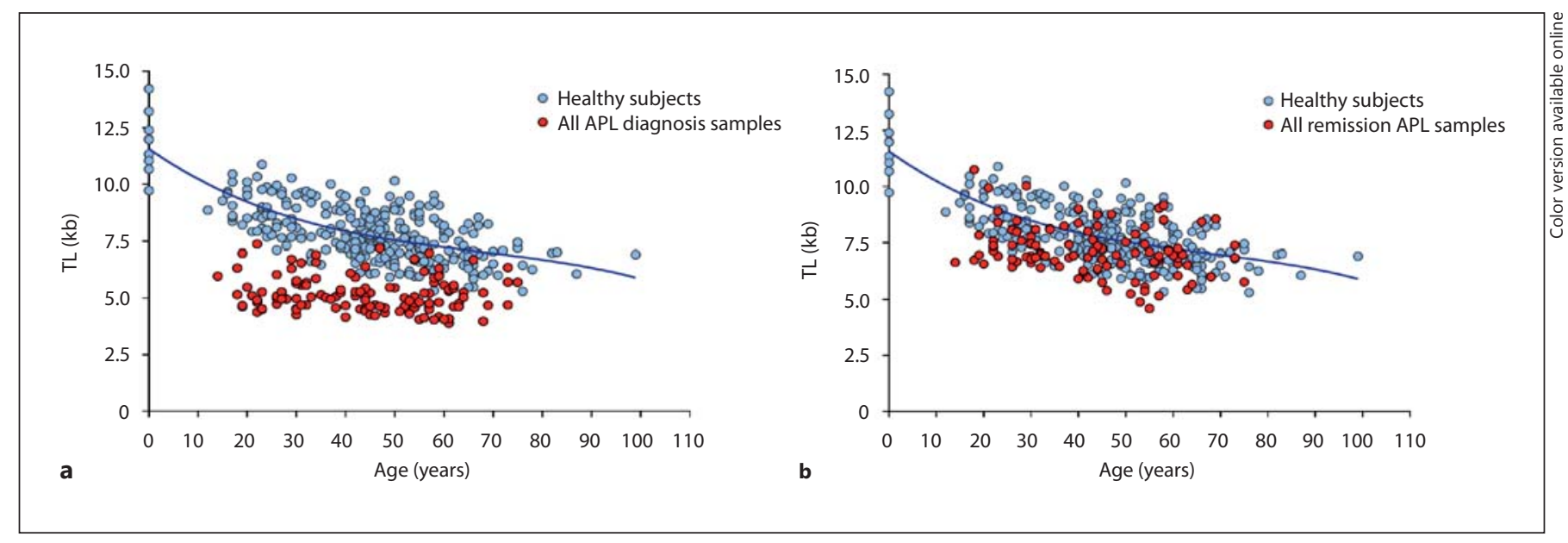

Fig. 1. TL at diagnosis (a) and remission (b), both displayed as TL (kb) over age (years) of APL patients compared to healthy, age-matched subjects.

Table 4. OS and DFS rates using stratified univariate and multivariable Cox PH regression models

\begin{tabular}{|c|c|c|c|c|c|c|c|}
\hline \multirow[t]{2}{*}{ Outcome } & \multirow[t]{2}{*}{ Parameter } & \multicolumn{3}{|c|}{ Univariate } & \multicolumn{3}{|c|}{ Multivariable $^{1}$} \\
\hline & & $\begin{array}{l}\text { events/ } \\
\text { total } \mathrm{n}\end{array}$ & $\begin{array}{l}\text { HR: long/short or } \\
\text { big/small ( } 95 \% \text { CI) }\end{array}$ & Wald p & $\begin{array}{l}\text { events/ } \\
\text { total } \mathrm{n}\end{array}$ & $\begin{array}{l}\text { HR: long/short or } \\
\text { big/small (95\% CI) }\end{array}$ & Wald $\mathrm{p}$ \\
\hline \multirow[t]{3}{*}{$\mathrm{OS}^{2}$} & TL at diagnosis (by Q3) & $49 / 186$ & $0.44(0.21-0.90)$ & 0.026 & $48 / 177$ & $0.65(0.29-1.45)$ & 0.29 \\
\hline & $\mathrm{TL}$ at remission (by Q3) & $24 / 143$ & $1.05(0.44-2.53)$ & 0.91 & $23 / 137$ & $1.36(0.50-3.69)$ & 0.54 \\
\hline & delta TL (by Q3) 3 & $21 / 140$ & $3.60(1.44-9.01)$ & 0.006 & $20 / 134$ & $3.51(1.20-10.31)$ & 0.02 \\
\hline \multirow[t]{3}{*}{ DFS } & TL at diagnosis (by Q3) & $37 / 159$ & $0.36(0.15-0.87)$ & 0.023 & $35 / 151$ & $0.43(0.16-1.14)$ & 0.09 \\
\hline & TL at remission (by Q3) & $30 / 143$ & $0.79(0.35-1.77)$ & 0.56 & $29 / 137$ & $0.82(0.34-2.00)$ & 0.67 \\
\hline & delta TL (by Q3) 3 & $27 / 140$ & $1.69(0.76-3.79)$ & 0.20 & $26 / 134$ & $1.30(0.51-3.29)$ & 0.58 \\
\hline
\end{tabular}

${ }^{1}$ Adjusted for ECOG PS (0 vs. 1 vs. $2-3$ ), WBC risk group (low vs. high), age, platelet count and hemoglobin.

${ }^{2}$ One patient in C9710 was missing a survival indicator.

${ }^{3}$ Defined as TL at remission minus TL at diagnosis.

\section{Longer Telomeres at Diagnosis Correlate with}

\section{Low-Risk Disease and Better Clinical Outcomes}

$\mathrm{TL}$ at diagnosis was significantly associated with disease risk status $(\mathrm{OR}=4.32,95 \% \mathrm{CI} 2.02-9.22 ; \mathrm{p}=0.0002)$. Our results indicate that a 1-kb-higher TL at diagnosis translated into a $332 \%$ increase in the odds of having lowrisk APL. The association between TL at diagnosis and APL risk status once again supported the finding of differences in TL at diagnosis in the 4 cohorts with different risk levels. Of the 187 patients with TL data at diagnosis, $160(85.6 \%)$ achieved CR and $13(7.0 \%)$ died early across all studies. Neither CR $(\mathrm{OR}=1.10,95 \%$ CI $0.60-2.00 ; \mathrm{p}=$ $0.76)$ nor early death $(\mathrm{OR}=0.62,95 \%$ CI $0.25-1.53$; $\mathrm{p}=$ 0.30 ) was significantly associated with TL at diagnosis.
A preliminary analysis of the impact of TL at diagnosis and delta TL on OS and DFS using the Akaike information criterion (AIC) values from the stratified univariate Cox $\mathrm{PH}$ regression models showed that using the third quartile (Q3) as the cut-off point to dichotomize TL fits the model best (i.e. this decreased the AIC value most from the null model) compared to using the first quartile (Q1), the median (Q2) or else TL on the continuous scale (data not shown; no significant difference in AIC values with respect to various cut-off points for TL at remission). Consequently, the HR (TL: long/short or delta TL: big/ small) and its 95\% CI with respect to OS and DFS were calculated using Q3 as the TL cut-off for each time point. Table 4 summarizes the HR and its corresponding 95\% 


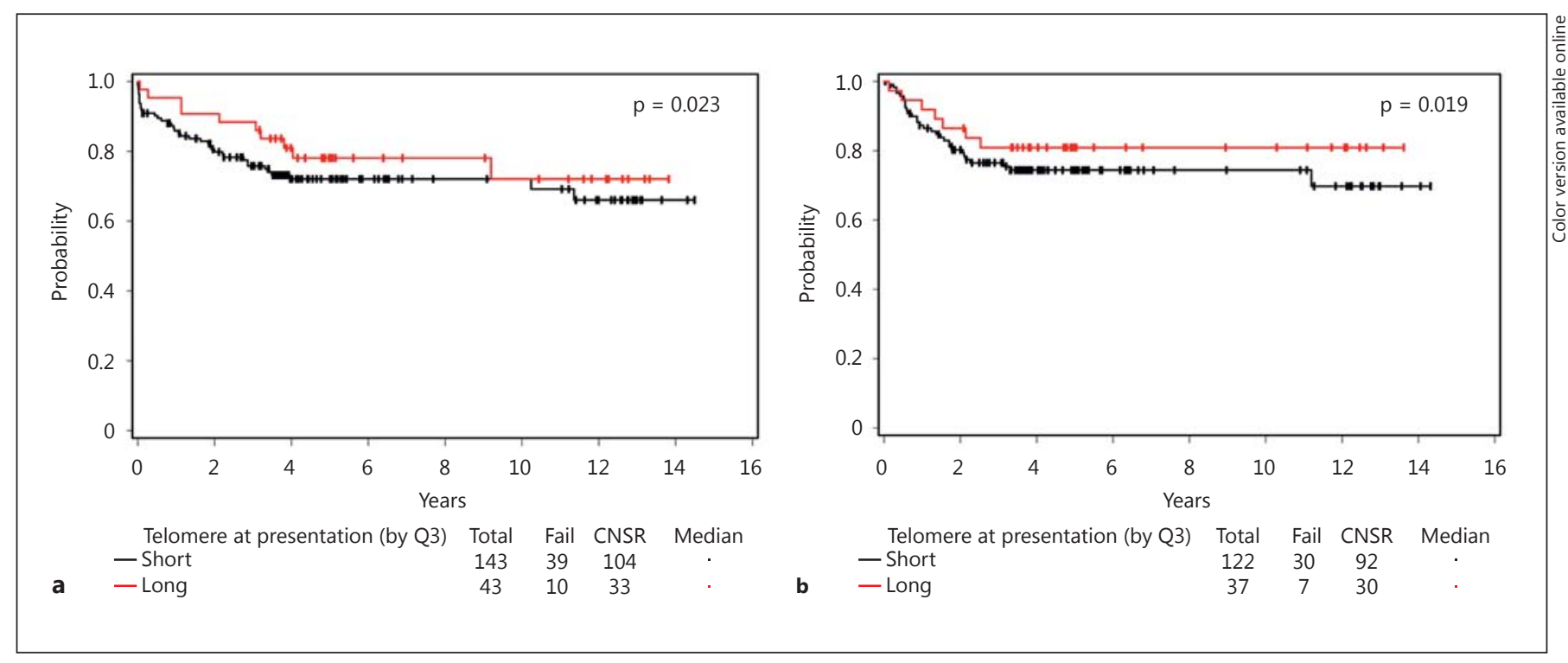

Fig. 2. OS (a) and DFS (b) curves according to short or long TL at diagnosis (with Q3 as the cut-off point).

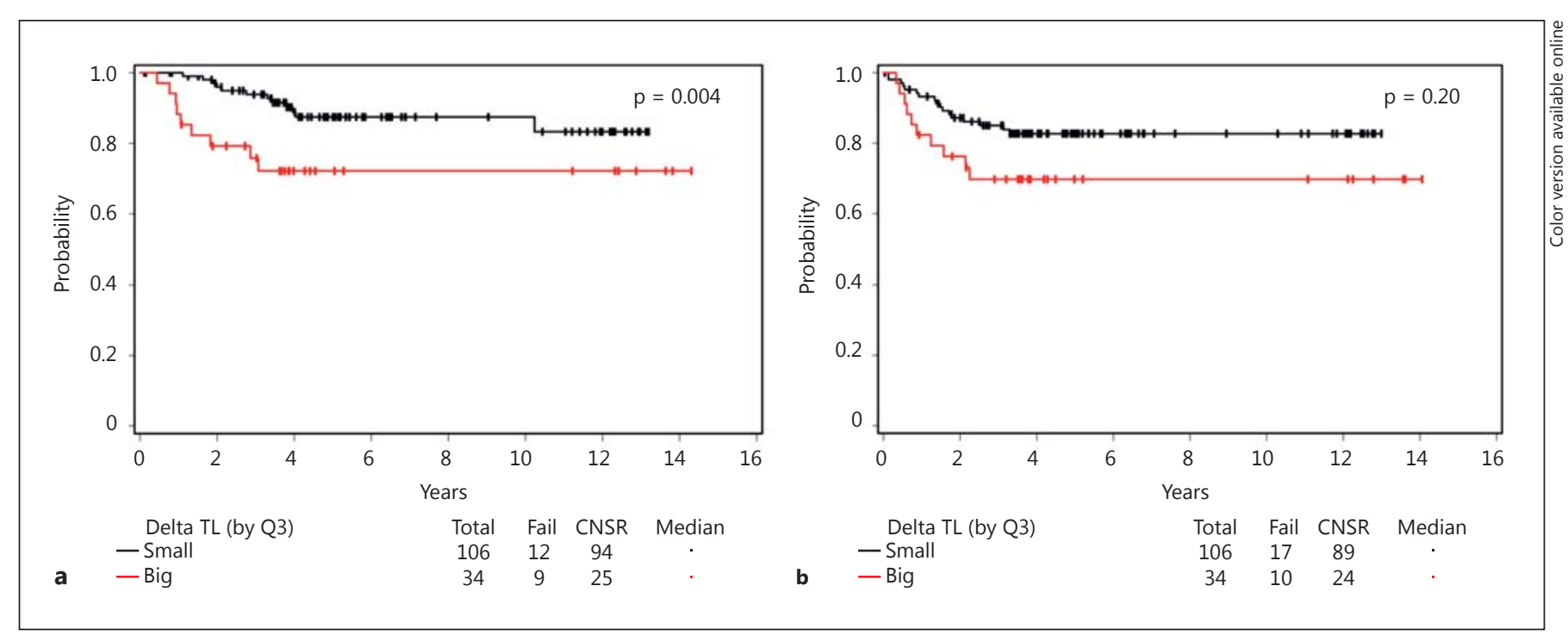

Fig. 3. OS (a) and DFS (b) curves according to small or big delta TL (with Q3 as the cut-off point).

CI for OS and DFS by disease time point, using univariate and multivariable Cox PH models. Both OS (log-rank p = 0.023; fig. 2a) and DFS (log-rank test, $\mathrm{p}=0.019$; fig. $2 \mathrm{~b}$ ) were statistically superior in patients who presented with longer telomeres. However, this effect on OS and DFS disappeared after controlling for risk status (low vs. high), ECOG PS ( 0 vs. 1 vs. $2-3$ ), age, platelet count and hemoglobin value (table 4). A Cox PH model with forward selection on all these baseline predictors showed that risk status was selected into the model first to predict either OS $\left(\chi^{2}=6.55, \mathrm{p}=0.0002\right)$ or DFS $\left(\chi^{2}=6.55, \mathrm{p}=0.01\right)$, followed by hemoglobin and then TL at diagnosis.

\section{TL in Remission Does Not Correlate with Clinical Outcomes}

Among the 143 patients with available TL in CR, 29 $(20.3 \%)$ relapsed. We found no statistically significant association between TL at remission and the likelihood of 
relapse $(\mathrm{OR}=0.96,95 \%$ CI $0.64-1.42 ; \mathrm{p}=0.82)$. Similarly, delta TL did not significantly associate with risk of relapse $(\mathrm{OR}=1.06,95 \% \mathrm{CI} 0.70-1.59 ; \mathrm{p}=0.79)$. TL at remission had no statistically significant effect on either OS (HR: long/short $=1.05,95 \%$ CI $0.44-2.53 ; \mathrm{p}=0.91$ ) or DFS (HR: long/short $=0.79,95 \%$ CI 0.35-1.77; $\mathrm{p}=0.56$ ).

We subsequently examined delta TL as it occurred during the disease course. For patients who achieved CR, this was the change in TL from the diagnosis of APL to $\mathrm{CR}$, with a positive delta TL indicating an increase in TL at remission. There was a negative correlation between TL at remission and TL at diagnosis (Spearman: $\rho=-0.27$, $p=0.0012$ ), suggesting that patients with shorter TL at diagnosis experience a bigger delta $\mathrm{TL}$, and patients with a longer starting TL tended to achieve a smaller delta TL.

TL Recovery (Delta TL) Is the Strongest Predictor of OS

Next, we analyzed the association of delta TL with clinical outcomes [change in TL (small vs. big) dichotomized by Q3 (at $2.7 \mathrm{~kb}$ )]. Patients with a small delta TL had significantly longer OS than patients with a big delta TL (HR: big/small $=3.60,95 \%$ CI 1.44-9.01; $\mathrm{p}=0.006$ ). Results from multivariable Cox regression indicated that delta TL remained a statistically significant predictor for OS (HR $=3.51,95 \%$ CI $1.20-10.31 ; \mathrm{p}=0.02)$ after adjusting for known risk factors (WBC risk status, ECOG PS, age, platelet count and hemoglobin value) at baseline. This effect of delta TL on OS was even more pronounced in patients who achieved a CR $\left(\chi^{2}=9.61, \mathrm{p}=0.002\right)$ compared to TL at diagnosis, age, ECOG PS, platelet count or hemoglobin value $\left(\chi^{2}=1.31,6.29,0.54,2.13,4.58\right.$ and 0.52 , respectively). A Cox model with forward selection on these predictors showed that delta TL was entered into the model first, followed by platelet count and then hemoglobin value. DFS was not statistically different between patients with small and big delta TL (log-rank test $\mathrm{p}=0.20$; fig. $3 \mathrm{~b})$.

\section{TERT and TERC Mutational Status in APL}

Sanger sequencing for the TERT and TERC genes of samples at diagnosis in the first 90 patients of this cohort failed to identify mutations, apart from the exon 2 codon 279 (GCC/ACC - Ala/Thr) and the exon 15 codon 1062 (GCC/ACC - Ala/Thr) polymorphisms in the TERT, which were identified at a frequency of 4.4 and $2.2 \%$, respectively. These rates are ultimately similar to those found in 528 previously reported healthy volunteers (1.9 and $1.3 \%, \mathrm{p}=$ 0.13 and $p=0.63$, respectively, by the Fisher exact test) [14] (online suppl. table 1S; for all online suppl. material, see www.karger.com/doi/10.1159/000448160). For the ob- served polymorphisms in our patients, sequencing of the remission samples showed the heterozygous presence of the same single nucleotide variants, consistent with a germline inheritance.

\section{Discussion}

The treatment of APL is among the most unique in the myeloid leukemias, and represents a major triumph in the field of hematologic malignancies. The exquisite sensitivity of PML/RARa containing leukemic promyelocytes to ATRA and ATO results in a cure rate of $85-90 \%$, provided that potentially lethal hemorrhagic complications at presentation or during induction are avoided [15]. To date, the most important prognostic factor in APL, besides age, and the sole factor influencing treatment decisions, has been the WBC count at presentation. Other biologic features, such as the PML/RAR $\alpha$ isoform [16], the expression of the neural cell adhesion factor CD56 [17] as well as additional cytogenetic abnormalities [18] or mutations in the FLT3 gene [19] have been considered and found to have prognostic impact in some but not all studies. Considering survivorship issues in APL patients as the final frontier in the management of this disease, identification of stronger predictors of the longterm outcome may prove invaluable, potentially directing post-remission therapy.

In the largest study of TL in APL patients analyzed to date, we investigated TL in 187 subjects enrolled across 4 intergroup trials. As seen in AML [4] and various solid tumors [20], DNA from untreated APL patients consistently had very short TL when compared with healthy individuals. We assumed that the low-density MNCs collected after the Ficoll gradient separation at diagnosis were all APL blasts. In fact, this cell fraction is frequently heterogeneous, particularly in APL cases with a low WBC count at presentation, in which the percentage of APL cells is typically much less than $100 \%$. Nevertheless, in our study, we did not find an association between TL and the percentage of leukemic promyelocytes, even though the DNA extracted from the entire MNC fraction of blood or bone marrow samples contained a median of $75 \%$ leukemic promyelocytes (range 13-99\%). As an adjustment to this variance, separating the APL promyelocytes with flow-cytometric sorting and analyzing a pure APL blast population could, in future trials, provide a more refined measurement of TL.

At diagnosis, TL was a statistically significant predictor of both DFS and OS. However, very short telomeres 
were associated with a higher WBC count, suggesting that the increased proliferative rate of the leukemic cells led to enhanced telomere attrition.

The only existing study of telomere biology in APL is a retrospective analysis of 32 newly diagnosed and 8 relapsed APL patients from a single institution [7]. In this particular study, telomerase activity was significantly higher in relapsed versus newly diagnosed patients, and a higher degree of TL recovery (corresponding to the delta TL in our study) was a predictor for longer OS. In our cohort, delta TL was the most powerful predictor of OS, more powerful than WBC risk status which currently stands as the only clinical parameter that segregates patients into low- and high-risk subgroups, ultimately informing treatment [5]. This biological association, now found in 2 independent retrospective APL cohorts, may appear paradoxical, as recovery to normal hematopoiesis with longer telomeres in circulating leukocytes should not be associated with poorer outcomes. As TL in remission is likely representative of the TL of normal hematopoietic cells, delta TL is a measure of the degree of telomere attrition occurring from the time of acquisition of $t(15: 17)$ in a normal myeloid stem/progenitor to the overt presentation of APL. Thus, a big delta TL identifies a group of patients with very active disease and inferior prognosis better than the WBC count at diagnosis of APL. In our analysis, we accounted for known clinical risk factors for poor OS in APL but we cannot rule out that other indicators of inferior outcome played a role in this patient population. Molecular markers such as FLT3-ITD [19], CD95 promoter polymorphism variants [21] or minimal residual disease by reverse-transcription PCR [22] have been proposed as relevant predictors of outcome, and are likely responsible for refractory/relapsed disease through various (postulated or proven) mechanisms. Telomere dynamics in recovery from APL should be investigated as an additional factor in identifying high-risk disease regardless of the available molecular mechanisms.

In patients with AML, germline mutations in human TERT have been described, with the most common mutation being 3 times more prevalent than in healthy controls [4]. In our analysis of APL patients, TERT mutations in exon 2 codon 279 (Ala/Thr) and polymorphisms in exon 15 codon 1062 (Ala/Thr) were identified at a frequency similar to that in normal healthy volunteers [14], consistent with $\mathrm{t}(15: 17)$ being sufficient to drive the leukemic process in APL [16]. Moreover, APL was not reported in a cohort of patients with telomere disease [23], making it unlikely that TERT mutations or short telomeres are associated with the acquisition of $\mathrm{t}(15: 17)$.
Recently reported phase III trials from Europe that utilized the ATRA/ATO combinations upfront across all APL risk subgroups did not explore the role of telomere dynamics in disease stratification and/or low rates of relapse $[24,25]$. Our findings on TL and delta TL in particular as powerful predictors of OS in APL warrant prospective confirmation. Given that most of the deaths in our analysis (all the E2491 cases and the majority of the C9710 cases) occurred in patients that did not receive primary ATO, this analysis needs to be applied in particular to updated and ongoing protocols that use upfront ATO. If corroborated, TL measurement may be useful as a simple and inexpensive parameter in disease risk stratification and as a meaningful predictor of OS in patients with APL.

\section{Acknowledgements}

This study was conducted by the ECOG-ACRIN Cancer Research Group (Robert L. Comis, MD, and Mitchell D. Schnall, MD, $\mathrm{PhD}$, Group Co-Chairs) and supported in part by Public Health Service Grants CA180820, CA180794, CA189859, CA180791, CA180816, CA180819, CA180821 and CA180790 and the National Cancer Institute, National Institutes of Health and the Department of Health and Human Services. Its content is solely the responsibility of the authors and does not necessarily represent the official views of the National Cancer Institute.

\section{Disclosure Statement}

The authors report no conflicts of interest.

$\begin{array}{ll}\text { References } & 1 \text { Blackburn EH: Switching and signaling at the } \\ & \text { telomere. Cell 2001;106:661-673. } \\ 2 & \text { Calado RT, Young NS: Telomere mainte- } \\ & \text { nance and human bone marrow failure. Blood } \\ & 2008 ; 111: 4446-4455 . \\ 3 & \text { Kim NW, Piatyszek MA, Prowse KR, Harley } \\ & \text { CB, West MD, Ho PL, Coviello GM, Wright } \\ & \text { WE, Weinrich SL, Shay JW: Specific associa- } \\ & \text { tion of human telomerase activity with im- } \\ & \text { mortal cells and cancer. Science 1994;266: } \\ & 2011-2015 . \\ 4 & \text { Calado RT, Regal JA, Hills M, Yewdell WT, } \\ & \text { Dalmazzo LF, Zago MA, Lansdorp PM, Hog- } \\ & \text { ge D, ChanockSJ, Estey EH, Falcão RP, Young } \\ & \text { NS: Constitutional hypomorphic telomerase } \\ & \text { mutations in patients with acute myeloid leu- } \\ & \text { kemia. Proc Natl Acad Sci USA 2009;106: } \\ & 1187-1192 .\end{array}$


5 Powell BL, Moser B, Stock W, Gallagher RE, Willman CL, Stone RM, Rowe JM, Coutre S, Feusner JH, Gregory J, Couban S, Appelbaum FR, Tallman MS, Larson RA: Arsenic trioxide improves event-free and overall survival for adults with acute promyelocytic leukemia: North American Leukemia Intergroup Study C9710. Blood 2010;116:3751-3757.

6 Tarkanyi I, Dudognon C, Hillion J, Pendino F, Lanotte M, Aradi J, Ségal-Bendirdjian E: Retinoid/arsenic combination therapy of promyelocytic leukemia: induction of telomerase-dependent cell death. Leukemia 2005;19: 1806-1811.

7 Ghaffari SH, Shayan-Asl N, Jamialahmadi $\mathrm{AH}$, Alimoghaddam K, Ghavamzadeh A: Telomerase activity and telomere length in patients with acute promyelocytic leukemia: indicative of proliferative activity, disease progression, and overall survival. Ann Oncol 2008;19:1927-1934.

8 Heiss NS, Knight SW, Vulliamy TJ, Klauck SM, Wiemann S, Mason PJ, Poustka A, Dokal I: X-linked dyskeratosis congenita is caused by mutations in a highly conserved gene with putative nucleolar functions. Nat Genet 1998; 19:32-38.

9 Vulliamy TJ, Walne A, Baskaradas A, Mason PJ, Marrone A, Dokal I: Mutations in the reverse transcriptase component of telomerase (TERT) in patients with bone marrow failure. Blood Cells Mol Dis 2005;34:257-263.

10 Vulliamy T, Marrone A, Goldman F, Dearlove A, Bessler M, Mason PJ, Dokal I: The RNA component of telomerase is mutated in autosomal dominant dyskeratosis congenita. Nature 2001;413:432-435.

11 Alter BP, Giri N, Savage SA, Rosenberg PS: Cancer in dyskeratosis congenita. Blood 2009; 113:6549-6557.

12 Tallman MS, Andersen JW, Schiffer CA, Appelbaum FR, Feusner JH, Ogden A, Shepherd L, Willman C, Bloomfield CD, Rowe JM, Wiernik PH: All-trans-retinoic acid in acute promyelocytic leukemia. N Engl J Med 1997; 337:1021-1028.
13 Winkler T, Hong SG, Decker JE, Morgan MJ, Wu C, Hughes WM 5th, Yang Y, Wangsa D, Padilla-Nash HM, Ried T, Young NS, Dunbar CE, Calado RT: Defective telomere elongation and hematopoiesis from telomerase-mutant aplastic anemia iPSCs. J Clin Invest 2013; 123:1952-1963.

14 Yamaguchi H, Calado RT, Ly H, Kajigaya S, Baerlocher GM, Chanock SJ, Lansdorp PM, Young NS: Mutations in TERT, the gene for telomerase reverse transcriptase, in aplastic anemia. N Engl J Med 2005;352:1413-1424.

15 Park JH, Qiao B, Panageas KS, Schymura MJ, Jurcic JG, Rosenblat TL, Altman JK, Douer D, Rowe JM, Tallman MS: Early death rate in acute promyelocytic leukemia remains high despite all-trans retinoic acid. Blood 2011; 118:1248-1254

16 Baljevic M, Park JH, Stein E, Douer D, Altman JK, Tallman MS: Curing all patients with acute promyelocytic leukemia: are we there yet? Hematol Oncol Clin North Am 2011;25: 1215-1233.

17 Murray CK, Estey E, Paietta E, Howard RS, Edenfield WJ, Pierce S, Mann KP, Bolan C, Byrd JC: CD56 expression in acute promyelocytic leukemia: a possible indicator of poor treatment outcome? J Clin Oncol 1999;17: 293-297.

18 Hiorns LR, Swansbury GJ, Mehta J, Min T, Dainton MG, Treleaven J, Powles RL, Catovsky D: Additional chromosome abnormalities confer worse prognosis in acute promyelocytic leukaemia. Br J Haematol 1997;96:314-321.

19 Au WY, Fung A, Chim CS, Lie AK, Liang R, Ma ES, Chan CH, Wong KF, Kwong YL: FLT3 aberrations in acute promyelocytic leukaemia: clinicopathological associations and prognostic impact. Br J Haematol 2004;125: 463-469.
20 Heaphy CM, Meeker AK: The potential utility of telomere-related markers for cancer diagnosis. J Cell Mol Med 2011;15:1227-1238.

21 Sunter NJ, Scott K, Hills R, Grimwade D, Taylor S, Worrillow LJ, Fordham SE, Forster VJ, Jackson G, Bomken S, Jones G, Allan JM: A functional variant in the core promoter of the CD95 cell death receptor gene predicts prognosis in acute promyelocytic leukemia. Blood 2012;119:196-205.

22 Chendamarai E, Balasubramanian P, George B, Viswabandya A, Abraham A, Ahmed R, Alex AA, Ganesan S, Lakshmi KM, Sitaram U, Nair SC, Chandy M, Janet NB, Srivastava VM, Srivastava A, Mathews V: Role of minimal residual disease monitoring in acute promyelocytic leukemia treated with arsenic trioxide in frontline therapy. Blood 2012;119:34133419.

23 Calado RT, Young NS: Telomere diseases. N Engl J Med 2009;361:2353-2365.

24 Lo-Coco F, Avvisati G, Vignetti M, Thiede C, Orlando SM, Iacobelli S, Ferrara F, Fazi P, Cicconi L, Di Bona E, Specchia G, Sica S, Divona M, Levis A, Fiedler W, Cerqui E, Breccia M, Fioritoni G, Salih HR, Cazzola M, Melillo L, Carella AM, Brandts $\mathrm{CH}$, Morra E, von Lilienfeld-Toal M, Hertenstein B, Wattad M, Lübbert M, Hänel M, Schmitz N, Link $H$, Kropp MG, Rambaldi A, La Nasa G, Luppi M, Ciceri F, Finizio O, Venditti A, Fabbiano F, Döhner K, Sauer M, Ganser A, Amadori S, Mandelli F, Döhner H, Ehninger G, Schlenk RF, Platzbecker U: Retinoic acid and arsenic trioxide for acute promyelocytic leukemia. $\mathrm{N}$ Engl J Med 2013;369:111-121.

25 Burnett AK, Russell NH, Hills RK, Bowen D, Kell J, Knapper S, Morgan YG, Lok J, Grech A, Jones G, Khwaja A, Friis L, McMullin MF, Hunter A, Clark RE, Grimwade D: Arsenic trioxide and all-trans retinoic acid treatment for acute promyelocytic leukaemia in all risk groups (AML17): results of a randomised, controlled, phase 3 trial. Lancet Oncol 2015; 16:1295-1305. 